This item was submitted to Loughborough's Research Repository by the author.

Items in Figshare are protected by copyright, with all rights reserved, unless otherwise indicated.

\title{
Public criminology, reflexivity and the enterprise university: experiences of research, knowledge transfer, and co-option with police forces
}

\section{PLEASE CITE THE PUBLISHED VERSION}

http://dx.doi.org/10.1177/1362480616689299

\section{PUBLISHER}

SAGE $\odot$ The Authors

VERSION

AM (Accepted Manuscript)

\section{PUBLISHER STATEMENT}

This work is made available according to the conditions of the Creative Commons Attribution-NonCommercialNoDerivatives 4.0 International (CC BY-NC-ND 4.0) licence. Full details of this licence are available at: https://creativecommons.org/licenses/by-nc-nd/4.0/

\section{LICENCE}

CC BY-NC-ND 4.0

\section{REPOSITORY RECORD}

Lumsden, Karen, and Jackie Goode. 2019. "Public Criminology, Reflexivity and the Enterprise University: Experiences of Research, Knowledge Transfer, and Co-option with Police Forces". figshare. https://hdl.handle.net/2134/23664. 
This is a pre-print version of: Lumsden, K. and Goode, J. (forthcoming) 'Public Criminology, Reflexivity and the Enterprise University: Experiences of Research, Knowledge Transfer, and Co-option with Police Forces.' Theoretical Criminology.

Public Criminology, Reflexivity and the Enterprise University: Experiences of Research, Knowledge Transfer Work and Co-option with Police Forces 
This is a pre-print version of: Lumsden, K. and Goode, J. (forthcoming) 'Public Criminology, Reflexivity and the Enterprise University: Experiences of Research, Knowledge Transfer, and Co-option with Police Forces.' Theoretical Criminology.

\begin{abstract}
This paper reflects on an enterprise project which aimed to build partnerships with police forces in England. In attempting to do 'public criminology' we were confronted with power dynamics which had to be negotiated in relation to internal and external organizational cultures, public management, and 'audit culture'. We focus on two levels of co-option experienced, in relation to the university and the police: 1) internal university pressures such as definitions of 'research' and 'enterprise', funding, and the terms of the 'contract' of the project and 2) external pressures when engaging with police including new public management principles, quick fixes and academics as a 'resource'. The discussion draws on data from field notes and interviews with police officers and staff.
\end{abstract}

Keywords enterprise, evidence-base, police-academic partnerships, policing, public criminology, reflexivity

\title{
Introduction
}

In this paper we contribute to discussions of 'public criminology' (Loader and Sparks, 2010a) by reflecting on our experiences of conducting research and knowledge transfer work with police forces in England within the context of the 'enterprise university' and evidence-based policing. The police as an institution have a long history of being secretive and resistant to outsider interference, but in recent years there has been a greater willingness to form partnerships with academics (Fleming, 2012; Fyfe and Wilson, 2012; Goode and Lumsden, 2016). We consider our activities to be a form of 'public criminology' which was 'contracted' insofar as it comprised a funded project involving direct engagement and collaboration with external stakeholders including the police. Burawoy (2005: 11) notes that 
This is a pre-print version of: Lumsden, K. and Goode, J. (forthcoming) 'Public Criminology, Reflexivity and the Enterprise University: Experiences of Research, Knowledge Transfer, and Co-option with Police Forces.' Theoretical Criminology.

'public sociology' and 'policy sociology' can often blur. In this case, we found ourselves operating on the shifting ground between two groups of clients (university and police) while attempting to engage in 'public criminology'.

We focus on attempts to co-opt 'public criminology' into serving two broad agendas - that of universities' commitments to 'enterprise' and the financial, political and professional constraints to which external users of research are increasingly subject. Two levels of cooption experienced during the project are reflected upon herein. First, we discuss the internal university pressures and dilemmas which had to be negotiated. These included: definitions of 'research' and 'enterprise' and issues around funding and contracting of the project. Second, we reflect on the external pressures encountered in interactions with police partners. These included the influence of new public management principles, a focus on 'quick fixes', and academics as a 'resource'. In attempting to $d o$ 'public criminology' we were confronted with challenges in our interactions with stakeholders, including the power dynamics which must be negotiated in relation to internal and external organizational, public management, and 'audit cultures' (Power, 1997; Strathern, 2000).

There is a need to value the 'public aspects' of 'criminological labour' and to develop greater understanding of those aspects which further or impede our efforts to have 'practical effects' (Chancer and McLaughlin, 2007: 168). We highlight how the practice of 'public criminology' can entail occasions in which the criminologist may feel they are treading a thin line between critical engagement and academic freedom; and becoming, in relation to one of the pathologies of 'policy sociology', a 'servant of power... sacrificing scientific integrity in the process' (Burawoy, 2004: 1611). We are concerned with a tension between the selfidentity of criminologists within the bounds of public engagement (i.e. in a normative sense 
This is a pre-print version of: Lumsden, K. and Goode, J. (forthcoming) 'Public Criminology, Reflexivity and the Enterprise University: Experiences of Research, Knowledge Transfer, and Co-option with Police Forces.' Theoretical Criminology.

the role of criminology in engaging with the social world), and the institutional context in which this takes place, which consists of a pervasive 'audit culture' and the rise of the 'enterprise' or 'entrepreneurial university' (Taylor, 2014). In the past few decades we have witnessed 'the transformation of the traditional liberal and Enlightenment idea of the university as a place of higher learning into the modern idea of the university as corporate enterprise whose primary concern is with market share, servicing the needs of commerce, maximizing economic return and investment, and gaining competitive advantage...' (Shore, 2008: 282). Although this research is UK centric, it is important to acknowledge that these developments are occurring across Anglophone jurisdictions. We highlight the ways in which 'public criminology' risks becoming institutionalized and managerialized, set within a context of 'fast academia' - behind which is 'a business model that has ushered in: the introduction of high student fees; the incursion of private providers; changing styles of management embedded in NPM [new public management]...' (O’Neill, 2014). We show how this 'business model' can define the kind of 'contract' which sets the parameters of the research and/or enterprise relationship between universities and external stakeholders.

\section{Public Criminology}

The problems faced by criminologists in their role as public intellectuals is part of a continuing series of dilemmas that social scientists have faced throughout modern history (Gattone, 2006). In the last decade there has been a renewed impetus in the form of Burawoy's (2004, 2005) call for 'public sociology' and calls for 'public criminology' (Uggen and Inderbitzin, 2010; Loader and Sparks, 2010a). Burawoy (2005: 11) distinguishes between four types of sociology: 'policy sociology', 'professional sociology', 'critical sociology' and 'public sociology', which in their combination form a 'division of sociological labour'. 
This is a pre-print version of: Lumsden, K. and Goode, J. (forthcoming) 'Public Criminology, Reflexivity and the Enterprise University: Experiences of Research, Knowledge Transfer, and Co-option with Police Forces.' Theoretical Criminology.

'Professional' and 'policy sociology' involve instrumental knowledge, while 'critical' and 'public sociology' involve reflexive knowledge.

In contrast to the debate which followed Burawoy's call for a public sociology, there has been far less discussion of these issues within criminology (Chancer and McLaughlin, 2007). However, the concept of 'public criminology' emerged earlier than 'public sociology' with the idea promoted by Carrabine et al. (2000; see also Garland and Sparks, 2000) and the first reference attributed to Uggen and Inderbitzin (2006). Burawoy's American Sociological Association speech was followed by Todd Clear who in his 2009 presidential address to the American Society of Criminology called for a "public research agenda that can sustain enlightened policy-making and potent innovation' (Rock, 2014: 413). Discussions of 'public criminology' also appear in special issues of Theoretical Criminology (Chancer and McLaughlin, 2007) and Criminology \& Public Policy (Uggen and Inderbitzin, 2010). For Loader and Sparks a 'public criminology' debate provides an attempt to address criminology's minor impact on crime and penal policies and to 'lay renewed claim to the field's social relevance' (2010a: 772). Uggen and Inderbitzin (2010: 725) highlight criminology's distinctive features which 'push the boundaries of public scholarship' and include interdisciplinarity, a subject matter that incites moral panics, and a practitioner base engaged in knowledge production.

Uggen and Inderbitzin (2010: 726) argue that a 'public criminology' could 'nurture the passion students bring to justice concerns while at the same time contributing to professional, critical, and policy criminology'. They outline four tasks of criminology: 'evaluating and reframing cultural images of the criminal'; 'reconsidering rulemaking'; 'evaluating social interventions'; and 'assembling social facts and situating crime in disciplinary knowledge'. 
This is a pre-print version of: Lumsden, K. and Goode, J. (forthcoming) 'Public Criminology, Reflexivity and the Enterprise University: Experiences of Research, Knowledge Transfer, and Co-option with Police Forces.' Theoretical Criminology.

An early example of 'public criminology' is 'newsmaking criminology' which entails criminologists using 'mass communication for the purposes of interpreting, informing and altering the images of crime and justice, crime and punishment, and criminals and victims' (Barak, 2007: 191). However, according to Loader and Sparks (2010a: 773) there are dangers of forcing 'authors or works into different boxes, of encouraging the view that each stance is a mutually exclusive criminological identity, and of suggesting that "public criminology" is a distinct position that criminologists might or might not choose to adopt.' Public scholarship involves research, teaching and the 'service roles of academic life' (Uggen and Inderbitzin, 2010: 728). This includes developing research questions in collaboration with external groups and communities, 'strategies such as service learning projects and relevant internships... to bring academics and students out of the classroom and into their communities', and in service roles 'offer[ing] testimony as expert witnesses, conduct[ing] research with diverse community organizations, and disseminat[ing]... work in local, national, and international media' (Uggen and Inderbitzin, 2010: 729).

In Public Criminology? Loader and Sparks (2010b) provide a critical exploration of the project of 'public criminology' through ideal types of academic engagement, ultimately proposing the idea of 'democratic under-labouring'. This entails 'contributing to a better politics of crime and its regulation' (Loader and Sparks, 2010b: 117). It is committed to the generation of knowledge, acknowledging that criminology has three distinct 'moments' including 'the moment of discovery', the 'institutional-critical moment', and the 'normative moment' (Loader and Sparks, 2010b: 125). These three 'moments' facilitate 'coherence to criminology's public role by reconstructing modes of thinking and acting that one already finds in contemporary criminology, rather than prescribing what it is that criminologists should (or should not) think and do' (Loader and Sparks, 2010b: 127). 
This is a pre-print version of: Lumsden, K. and Goode, J. (forthcoming) 'Public Criminology, Reflexivity and the Enterprise University: Experiences of Research, Knowledge Transfer, and Co-option with Police Forces.' Theoretical Criminology.

Wacquant (2011: 439) argues that Loader and Sparks deliver 'a strong incitement to reflexivity... insofar as it invites its readers to think through criminological issues as they relate to politics and policy, rather than accept them as pre-packaged'. He also highlights three weakness in their thesis including: a focus on the American 'public sociology' controversy, the adoption of a 'textualist brand' of reflexivity which ignores institutional aspects; and the utilisation of a descriptive typology (Wacquant, 2011: 439). Currie (2007) argues that the 'democratic under-labourer' provides an unrealistic view of the political arena, which consists of different groups with different ideologies and power imbalances. There are also a number of more general critiques of 'public criminology' (Rock, 2010). Tittle (2004) for example, draws attention to the moral dilemmas faced by criminologists, the 'shaky' (and ever-changing) ground on which criminological knowledge is based, and related threats to the legitimacy of sociological knowledge. He cautions that most of the time we 'do not know as much as we pretend' to (Stanko, 2008) and practitioners rarely trust sociological knowledge (Tittle, 2004: 1641).

\section{Reflexivity in Criminology}

While agreeing with Rock (2010: 764) that a 'public criminology must be reflexive about itself, its possibilities, and the world on which it seeks to act', we argue that calls for 'public criminology' have not yet been complemented by an availability of such reflexive accounts, guidance on how this should be done in practice, or on the experiences of researchers engaging with various publics or stakeholders. Lumsden and Winter (2014: 2) note that: 'Reflexivity... draws our attention to the ways in which knowledge is produced not just by the academic, but in collaboration (and often conflict) with the researched and those in positions of power who grant us access...' 
This is a pre-print version of: Lumsden, K. and Goode, J. (forthcoming) 'Public Criminology, Reflexivity and the Enterprise University: Experiences of Research, Knowledge Transfer, and Co-option with Police Forces.' Theoretical Criminology.

Although criminology has a less prominent legacy of producing public reflexive accounts than in sociology or anthropology for instance, recent publications such as Lumsden and Winter's (2014) Reflexivity in Criminological Research, and the writings of others such as Jewkes (2012) and Liebling (1999), demonstrate the growing recognition amongst criminologists of the value of reflexivity, in addition to feminist criminologies. As Gelsthorpe and Morris (1990: 88) point out, the feminist principle involves 'viewing one's involvement as both problematic and valid and of recording the subjective experiences of doing research, for these experiences underpin the creation of knowledge'. Theoretical developments in feminist criminology have begun to permeate mainstream criminology, and the benefits of research methodologies favoured by feminist criminologists are gradually being recognised by other streams of criminology (Mason and Stubbs, 2010). Reflexivity challenges the myth of 'hygienic research' (Oakley, 1981) and 'reminds us that those individuals involved in our research are "subjects", not "objects", and therefore "they should not be treated as would a chemist treat a chemical substance or a geologist would treat a rock' (Jupp, 1989: 130). It permeates 'all aspects of the research from selection of the research topic, search for funding, access to and engagement with participants and settings, data collection, analysis, interpretation, dissemination, application of findings, and our theoretical and methodological location...' (Lumsden and Winter, 2014: 2).

Chan (2000: 131-132) argues that it is also crucial that we examine the proliferation of contracted research because there is a risk that the 'acceleration of these trends will spell the end of critical - reflexive - criminology'. As Lumsden (2016: 23) notes: 'Critical reflections in studies where the researcher is in an underprivileged position, such as those involving powerful groups can make public reflections difficult, and raises questions as to how 
This is a pre-print version of: Lumsden, K. and Goode, J. (forthcoming) 'Public Criminology, Reflexivity and the Enterprise University: Experiences of Research, Knowledge Transfer, and Co-option with Police Forces.' Theoretical Criminology.

researchers avoid becoming "servants of power" in doing "policy sociology"...' Therefore,

before we reflect upon our experiences of doing 'public criminology' with the police, we briefly 'surface' issues of power and status within different models of 'partnerships', by outlining the history of policing research.

\section{Policing Research and Police-Academic Partnerships}

A diverse and frequently divergent and disputatious literature on and within the field of police studies exists. As Manning (2005) notes police studies has typically involved a distinction between 'sociology of' and 'sociology for' the police. A similar observation is made by Innes (2010: 128) who argues that it can act as a 'mirror' or a 'motor': either reflecting the 'complex realities of policing in a globalizing world' or working as an “"engine” for change and improvement'.

The traditional perspectives in police studies include ethnographic approaches (Cain, 1979; Holdaway, 1983; Punch, 1985) which helped to 'foreground the question of how deviance is produced' by the police and to shift attention from the deviant to agencies of social control (McLaughlin, 2007: 49-50). Later work includes Marxist perspectives concerned with the ‘injustices of police-state-class relationships' (McLaughlin, 2007: 59). This includes Chevigny's (1969) Police Power and Hall et al.'s (1978) Policing the Crisis. Applied research perspectives developed at the same time as ethnographic and Marxist studies also worked to verify 'key policing facts' such as whether increasing the number of patrol officers in certain areas would reduce crime (McLaughlin, 2007: 67-68), and includes Goldstein's (1990) 'problem-oriented policing' and Wilson and Kelling's (1982) 'broken windows' thesis. Left realists (Lea and Young, 1984) worked to develop an alternative path to Marxism's 'idealist' position on policing arguing that 'crime is an endemic product of the 
This is a pre-print version of: Lumsden, K. and Goode, J. (forthcoming) 'Public Criminology, Reflexivity and the Enterprise University: Experiences of Research, Knowledge Transfer, and Co-option with Police Forces.' Theoretical Criminology.

class and patriarchal structure of advanced capitalist societies' (McLaughlin, 2007: 79). Cain

(1993) argues that the most recent sub-discipline of police studies has (as a result of funding decisions) focused on 'policy-oriented methodologies' which have been used to 'colonize the soul of police studies' (McLaughlin, 2007: 85) and focus on development of a 'what works' paradigm. The consequences of this include the 'drying up of ethnographically based indepth research monographs' (a concern also highlighted by Manning (2005)), and an absence of Marxist scholars from the field (McLaughlin, 2007: 85).

The focus has largely shifted from conducting research 'on' police, to conducting research 'with' police (Goode and Lumsden, 2016), and in recent years academics and policepractitioners have openly reflected on the benefits of police and academics working together (Fleming, 2012; Fyfe and Wilson, 2012; Stanko, 2008). Sheptycki (1994: 126-129) distinguishes between three ways of conducting police research including: academics researching the police - 'the case of the outsider'; police researching the police - the case of the 'insider' out; and in-house police research - the case of the insider and the 'outsider in'. As Canter (2004: 109) notes it is out of the interaction between police and academic cultures 'as sort of miscegenation', that more effective policing will emerge. He highlights three distinctions between police and academic cultures as including 'ways of knowing', 'ways of acting' and the various 'objectives' that motivate actors within these contexts. The traditional relationship between police and academics has been conceptualized as 'two worlds' consisting of a 'dialogue of the deaf', which can be understood as a 'mutual misunderstanding that negatively impacts on the police-academics relationship' (Bradley and Nixon, 2009: 423). Academics have previously been criticized for failing to engage with the complex demands of policing resulting in 'a lingering cultural mistrust between police and academia that can hinder research partnerships' (Wilkinson, 2010: 147). Stanko (2007) 
This is a pre-print version of: Lumsden, K. and Goode, J. (forthcoming) 'Public Criminology, Reflexivity and the Enterprise University: Experiences of Research, Knowledge Transfer, and Co-option with Police Forces.' Theoretical Criminology.

highlights four reasons for the difficulties 'outsiders' encounter when trying to translate research into evidence in the realm of policing. Firstly, they are often unaware of the best means to target their audience. Secondly, they might be an expert in one area of academia, but in policing they are required to demonstrate expertise in multiple areas. Thirdly, there is a need for patience. Finally, there is a need to recognise the organizational context and power dynamics at play within it. Police organizations are 'breathing decision-making entit[ies]... [with]... "snakes and ladders" of change. To move forward, you need continuity, high organizational management support and a constitution of steel' (Stanko, 2007: 215). Thus, police and researchers have drawn attention to the benefits of co-produced research and participatory action research for shaping successful police-academic collaborations and research agendas (Foster and Bailey, 2010), but also offer some caveats.

'Partnerships' in the context of police-academic relations are focused on breaking down the 'two worlds' of policing and academia (Bradley and Nixon, 2009), to cultivate mutual understanding and develop close relationships in which researcher/s and practitioner/s work closely together to design, develop, conduct and disseminate research into the policing context. They can be top-down strategically developed partnerships, instigated and promoted at the organizational level, or bottom-up organically developing partnership relationships between key individuals from both sides. Our experience here is of the latter form of partnership, which was then co-opted into strategically aligned organizational priorities for forces and universities. We show how in practice academics may find themselves situated between the police organization and the university organization, having to respond to pressures in practice with regards to the definition, shaping and application of research. 
This is a pre-print version of: Lumsden, K. and Goode, J. (forthcoming) 'Public Criminology, Reflexivity and the Enterprise University: Experiences of Research, Knowledge Transfer, and Co-option with Police Forces.' Theoretical Criminology.

An Enterprise Project: Strategic Partnership Development with Police Forces

The discussion is based on our experiences during a one-year funded enterprise project from 2014-2015 that focused on developing partnerships and conducting knowledge transfer with police forces in England. As Foster and Bailey (2010) note, many partnerships of this type can emerge by 'happenstance', and this was the case in terms of early collaborative work and the development of this strategic project, both of which emerged from an informal meeting which the Principal Investigator (PI) had with a Superintendent responsible within his force for developing partnerships with regional universities. The project that emerged involved the appointment of a full-time Senior Research Associate (SRA), in a role similar to a Knowledge Transfer Manager, who spent seven months seconded to one police force, while also liaising with officers from four other regional forces, the College of Policing, and relevant stakeholders and practitioners (such as victim support agencies). We were working in a context where the contacts we made with the various police forces were open and receptive to dialogue and building partnerships with academia.

The aim of the project was to strategically develop a university partnership with regional police forces, showcasing research in the social sciences (and cognate disciplines), which was applicable in various policing contexts, and developing research collaborations and opportunities. The pot that the funding was secured from (via the university's Enterprise Project Grant) was the Higher Education Innovation Fund (HEIF). This knowledge transfer funding provided by the Higher Education Council for England (HEFCE) aims to 'support and develop a broad range of knowledge-based interactions between universities and colleges and the wider world, which result in economic and social benefit to the UK' (HEFCE, 2016). ${ }^{1}$ 
This is a pre-print version of: Lumsden, K. and Goode, J. (forthcoming) 'Public Criminology, Reflexivity and the Enterprise University: Experiences of Research, Knowledge Transfer, and Co-option with Police Forces.' Theoretical Criminology.

It was made clear to us by the police from the outset of the project that they were no longer able to accommodate the kind of 'informal', one-to-one relationships that have traditionally been created between lone academics and individual officers to undertake research of 'limited' interest and questionable 'applicability'. Rather, they would be open only to collaborative ventures which clearly mapped onto their own 'strategic priorities'. In order therefore to identify areas of common ground and interest, (while still holding open in our own minds the possibility of identifying potential questions which might not currently appear on their agenda), a scoping exercise was undertaken to identify policing-related research being conducted across the university. Once the full-time secondment of one of the authors was underway, a similar exercise was undertaken within the police force to determine areas where the two might match up and to identify what potential there was for future research collaborations. This included identifying completed university projects which had potential application to policing (which could be shared with them by academics willing to give presentations to the police on their work/area of expertise). We also researched within the context of the police forces themselves what their research needs and priorities were, and how these could be addressed collaboratively both presently, and in the future.

On the basis that our model of 'knowledge transfer' was not a uni-directional 'from on-high to-low' transmission-based one, but rather conceptualised as a collaborative process through which partners engage in the co-production of knowledge (including the joint identification of appropriate 'research questions'), we felt it important to gain some insight into police 'understandings' of what constitutes research. That is, we wanted to understand more about the 'research-related' territory within police forces within which we were operating. We conducted qualitative research into police perspectives of research and evidence-based policing. Fifteen semi-structured interviews were conducted with police staff and officers 
This is a pre-print version of: Lumsden, K. and Goode, J. (forthcoming) 'Public Criminology, Reflexivity and the Enterprise University: Experiences of Research, Knowledge Transfer, and Co-option with Police Forces.' Theoretical Criminology.

who had key roles in relation to the utilization of 'research evidence' or had experience of undertaking research themselves and/or collaborating professionally with academics. The interviews were all recorded and fully transcribed.

These were supplemented with data collected via our own observations during the setting-up and reviewing of our collaboration(s). This included observations and notes taken during our attendance at relevant meetings and at research fairs; and informal conversations with a variety of police personnel including representatives from probationary Constable level to Assistant Chief Constable level. Officers were also observed and shadowed on response shifts, in a custody suite and in a control room. Hence, the above constitutes a 'purposive' rather than a 'representative' sample. For ethical reasons the identities of the police forces, officers and staff in question have been fully anonymized. When drawing on our observations and field notes we utilise pseudonyms to disguise the identities of individuals.

\section{Reflections on Doing Enterprise Work with (or for) Universities and Police Forces}

\section{Internal Organizational Pressures from an Enterprise University}

a) Defining Research and Enterprise: Blurry Boundaries

Social scientists unfamiliar with enterprise have to navigate new terrain in terms of familiarising themselves with how universities typically define and distinguish between 'research' and 'enterprise' activities. The separation between the two does not 'fit' easily within a social science context or in relation to the types of organizations and settings with which social scientists generally engage. For instance, on writing the proposal for funding and setting-up the project, the PI was advised by the panel reviewing the proposal that '...the deliverables for the project were overly focused on the potential for further research and funding bids rather than knowledge transfer' (personal email correspondence, December 
This is a pre-print version of: Lumsden, K. and Goode, J. (forthcoming) 'Public Criminology, Reflexivity and the Enterprise University: Experiences of Research, Knowledge Transfer, and Co-option with Police Forces.' Theoretical Criminology.

2013). The aims of the enterprise project had to involve the creation of some tangible, measurable output which would generate future income in terms of individual work projects and future research, and with the instrumental goal of building collaborations and attracting future funding. We had no problem with the idea of putting in place 'memoranda of understandings' between the university and regional forces, but were highly troubled by a situation in which 'instrumental knowledge' appeared to be viewed as more important than 'reflexive knowledge' (Burawoy, 2005), reflecting a shift to notions of research as a 'product', with 'off the peg' solutions to problems. This raises broader issues around the way that criminologists may be asked by funders to revise their original plans to meet the requirements of the awarding body (in this case the university itself), if they are to secure funding.

Key to the challenges faced by social scientists when 'doing enterprise' aimed at 'knowledge transfer' is that the model of enterprise thrust upon them is one borrowed from disciplines more typically aligned with industry, such as science or engineering. The model of knowledge in use is of a 'product' which can be 'transferred' in a uni-directional way - as opposed to the collaborative process of knowledge production and sharing - a process which requires an understanding of the community one is seeking to join/create/participate in if knowledge is going to be effectively co-produced, shared and translated into practice. It is not that as social scientists we reject the application of our work or 'enterprise' in principle, but that we are too often constrained by having to work with a 'one-size-fits-all' model of enterprise that is in fact ill-suited for arts, humanities and social science disciplines. It may also not be a good fit with the 'needs' of some partners, as we shall see. 
This is a pre-print version of: Lumsden, K. and Goode, J. (forthcoming) 'Public Criminology, Reflexivity and the Enterprise University: Experiences of Research, Knowledge Transfer, and Co-option with Police Forces.' Theoretical Criminology.

The project had to link in with what were at the time 'emerging' university research themes

(known as 'Research Challenges') - cross-campus collaborations between academics from various disciplines conducting research in a shared area of work, supported (and to some extent 'controlled') by central 'Research and Enterprise Office' personnel. We were advised when writing the application to ensure it related strongly to the university's research strategy, and to identify a particular theme. Although the project could have been defined in relation to more than one of the 'Challenges', it was 'assigned' to the 'Secure and Resilient Societies' Research Challenge, led by a Professor from the Business School (rather than to another of the Challenges led by a Professor from the Social Sciences Department). The rhetoric around these Challenges is that they are not mutually exclusive and indeed we consciously worked in a 'cross-Challenge' way. Nevertheless, there is a risk that in 'managing' the activities and research of academics in this way, universities will seek to audit and control which areas of research are focused upon (for instance those which are most 'profitable' or 'en vogue'). This represents a potential threat to intellectual freedom including to criminological research which entails knowledge for 'knowledge's sake' (i.e. pure forms of research). To some extent, therefore, the project was co-opted into university strategic agendas from the outset, and we were at different times 'courted' or 'ignored' by Challenge Lead(s) as judgements were made about the potential of our project to generate smaller or larger future income streams. We found early on that "the "pure science" position that research must be completely insulated from politics is untenable, since antipolitics is no less political than public engagement' (Burawoy, 2004: 1605).

\section{b) Funding and Contracts}

We faced a further tension in that the funding had to be spent by the financial year end, and this impacted on how quickly the PI had to recruit a SRA and begin the lengthy contracting 
This is a pre-print version of: Lumsden, K. and Goode, J. (forthcoming) 'Public Criminology, Reflexivity and the Enterprise University: Experiences of Research, Knowledge Transfer, and Co-option with Police Forces.' Theoretical Criminology.

process between university and police force(s) before any programme of work could begin.

This included the writing up and negotiation of terms between university, police force, Police Crime Commissioner, and individual researchers for a 'Collaboration Agreement'. This also reflects the move to both 'fast' scholarship and short-term contracted research, militating against the space required for reflection and learning in terms of research, knowledge production and the building of relationships with research users - in this case police forces and individual officers from across police organizations. O'Neill (2014) writes about the increasing emphasis on 'fast academia' and 'ninja-like productivity' and how these relate to 'negative managerialism, health and well-being', and this can equally be applied to enterprise activities. In terms of the uncertainty of when the Collaboration Agreement would be agreed upon, for example, and when the project would be able to begin, the PI had many stressful and sleepless nights wondering whether the project would be able to start on time and would therefore succeed or fail. The process from announcement of the award to the final signing of the Collaboration Agreement between the university and the police took almost 5 months (from March 2014 to July 2014), during which time the PI had to keep the Police Lead on board, knowing that he would be similarly engaged with his colleagues. The inherent stress for all in this situation was illustrated, when the Agreement was finally in place, by an email he sent which read, 'I threw a party on hearing the news!'

An additional note is apposite here in relation to terminology. As noted earlier, the fundholder was given a firm 'steer' in relation to shifting the framing of the project away from 'research' and towards 'enterprise'; and yet the only title available for the position was 'PI' a term which is indicative of the role of 'doing research'. The majority of the project funding was allocated to the appointment of the SRA to a one-year fixed-term post. In fact, the appointee (joint author) was an experienced researcher/ethnographer who also understood the 
This is a pre-print version of: Lumsden, K. and Goode, J. (forthcoming) 'Public Criminology, Reflexivity and the Enterprise University: Experiences of Research, Knowledge Transfer, and Co-option with Police Forces.' Theoretical Criminology.

realpolitik of the 'enterprise university' sufficiently to 'manage' blurry boundaries and to undertake the role in a reflexive way. This does raise the question, however, of what kind of background is being sought when recruiting to such posts, which are now proliferating across the sector. Although clearly beyond the scope of this single project/article, it would be interesting to track future appointments to academic projects designated as 'enterprise' and to analyse the impact of such appointments on the shaping of 'public sociology/criminology'. Even for an ethnographer with over twenty years' experience, (as in this case), the tensions between university definitions and expectations of 'delivering' research and/or enterprise 'outcomes' on the one hand; and between meeting the expectations of the university while managing the constraints of a hierarchical police organisation which also offered (and intermittently withdrew) opportunities/permission to cross status boundaries on the other, were considerable. Universities need to give real consideration to the kinds and level of skills required for such posts and then be committed to funding them appropriately.

\section{External Organizational Pressures: Police Culture(s)}

a) (New) Public Management Principles

We found that public management principles and ideologies drove the dialogue and decisionmaking process regarding the 'value' of certain forms of research and inquiry. Police officers' understandings of research in the current evidence-based policing context, coupled with public sector austerity, presents challenges for social sciences, arts and humanities researchers, whose methodologies and critical standpoints might be at odds with the randomised control trials (RCTs) and crime science discourses that evidence-based policing promotes - as demonstrated by this police officer's discussion of what constitutes 'academic robustness': 
This is a pre-print version of: Lumsden, K. and Goode, J. (forthcoming) 'Public Criminology, Reflexivity and the Enterprise University: Experiences of Research, Knowledge Transfer, and Co-option with Police Forces.' Theoretical Criminology.

It's the new buzzword ... because I've sat through what seems like an awful lot of presentations about it. And it usually involves a ladder of a kind - this is a study which doesn't really have much academic robustness... and then at the top you've got this kind of sampling... which is very, very robust. (Interviewee 5 -Temporary Inspector)

We were struck by the extent to which, for police officers, research had been incorporated and was increasingly understood under the evidence-based policing (EBP) mantle (Lumsden and Goode, 2016). However, there were also examples of officers referencing the need for research approaches which would not fit the evidence-based gold standard of randomised control trials (RCTs) and systematic reviews privileged by the Maryland Scale. At a continuing professional development event on victims and the criminal justice system which we organized as part of the project our observation notes record instances of officers referring to the need for more data on victims' experiences of police and criminal justice, particularly of a kind which focused on victims' stories or narratives. Here, officers were citing the need for primarily qualitative research typical of the social sciences, arts, and humanities, which would offer further insight into the needs of victims. The need for qualitative research was also identified by officers in interviews, often after having defined 'research' earlier in the interview in the narrow terms of the EBP model but without recognising the inherent paradoxes within their accounts.

Some interviewees referred to financial benefits as the principal rationale guiding the adoption of evidence-based policing - 'doing more, with less'. We faced challenges in terms of being expected to demonstrate to the police that there were 'worthwhile' benefits of research collaborations which went beyond or were outside of immediate financial savings 
This is a pre-print version of: Lumsden, K. and Goode, J. (forthcoming) 'Public Criminology, Reflexivity and the Enterprise University: Experiences of Research, Knowledge Transfer, and Co-option with Police Forces.' Theoretical Criminology.

When asked about knowledge transfer, for example, interviewee 1 (police staff) warned of the dangers of being co-opted:

If I was to look at it as an outsider, knowing what I know, and thinking what would be the best way of facilitating or trying to introduce some measure of knowledge transfer, the first thing I would do is ... I would try to avoid it becoming part of the Force agenda, part of the higher management agenda...

In other words, we were being alerted to a risk here that knowledge transfer becomes a means of reaffirming organizational decisions. As Innes (2010: 129) points out: 'There is "dirty work" involved in getting research evidence to inform the implementing of organizational change, especially in a politically charged policy environment'.

We encountered instances of police expecting academics to contribute research or other activities 'in-kind', despite the cost or time involved. There was often an assumption that academics have 'time to spare', whereas police officers face demands from all sides. These expectations alerted us to the risks we were facing as academics in terms of becoming 'servants of power' (Burawoy, 2004); a risk demonstrated by the competing expectations documented in field notes from an early meeting between representatives of regional universities ('Sarah', 'Hannah' and the SRA) and regional police forces ('Bob' and 'Ryan') to discuss how partnership working might get off the ground in a more coordinated way and how arrangements might be organized and funded:

"Sarah commented that if the universities are putting money in, the Business Case needs to include what's in it for the universities ... although she had said that [they] 
This is a pre-print version of: Lumsden, K. and Goode, J. (forthcoming) 'Public Criminology, Reflexivity and the Enterprise University: Experiences of Research, Knowledge Transfer, and Co-option with Police Forces.' Theoretical Criminology.

probably would put a membership fee in, she also commented that they saw it as a long-term investment, with income generation being less important than being able to demonstrate the impact of their research. Bob talked in terms of a pot of $£ 100-150 \mathrm{k}$ ... being available for research and consulting. Sarah talked of it in terms of 'a pot to draw on to fund PhD students and RAs'. And Ryan came in with the question of 'why they couldn't continue getting $\mathrm{PhD}$ students to do their research for them "for free"'? He clearly didn't understand how PhDs are funded and Sarah talked in terms of some being paid for, some paying for themselves and some needing bursaries. Bob jumped in to explain that if you're getting something for free, you're not necessarily getting much input into what the research sets out to do and how it's done; and Hannah and I both commented here ... on the idea that the [group] is trying to develop a different model to that - not precluding small-scale doctoral studies, but something more genuinely collaborative, bigger and longer-term ...” (Field notes, September 2014)

Competing nodes of institutional governance were also highlighted as a challenge by an academic at a meeting we attended on evidence-based policing:

... 'this one is fraught with difficulties... knowledge transfer doesn't take place in a vacuum... [My university] wants to treat my engagement with the police as income generation and not be subsidizing costs - and the police are doing the same.... So how do we find a space?' (Field notes, January 2015)

At the same time as being alerted to the danger of being 'co-opted' into aligning ourselves solely with organizational aims such as local crime reduction targets or demand management needs, or being informally 'commissioned' to do 'their' research for free, we found that the 
This is a pre-print version of: Lumsden, K. and Goode, J. (forthcoming) 'Public Criminology, Reflexivity and the Enterprise University: Experiences of Research, Knowledge Transfer, and Co-option with Police Forces.' Theoretical Criminology. secondment was becoming akin to a form of 'organizational ethnography'. It was difficult to switch off our 'criminological imagination' (Young, 2011) while being introduced to and immersed in a police organizational culture, especially as analysis of organizational drivers and constraints would afford insight into the possibilities for transferring knowledge e.g. on approaches to 'demand management', already 'produced'/held by some of our academic Business School and/or Systems Engineering colleagues.

\section{b) Research as a 'Quick Fix' and Academics as a 'Resource'}

We encountered misconceptions from stakeholders as to what academic research entailed and the turn-around time of a research project. Forces and staff often wanted 'quick fixes' (Wilkinson, 2010) and to this end tended to conflate academic research and consultancy work. The SRA was often viewed by police as a 'resource'. The timescales they would anticipate in terms of turn-around were often unfeasible and/or their attention would have moved to another policing issue within a very short space of time, highlighting the 'reactive' nature of policing (Foster and Bailey, 2010). Managing the expectations of stakeholders was an ongoing challenge. The feeling that the SRA was viewed as a 'resource' is reflected in the field note below from a meeting with police:

Bob asked me ... how I saw my role and I talked in very general terms ... He thought that all sounded good, but had also come with a plan of his own for how I will spend my time with them... I did feel at the end as though I'd been recruited into the police, despite the fact that Bob is very pleasant - but that's probably a taster of police culture/style. (Field notes, September 2014) 
This is a pre-print version of: Lumsden, K. and Goode, J. (forthcoming) 'Public Criminology, Reflexivity and the Enterprise University: Experiences of Research, Knowledge Transfer, and Co-option with Police Forces.' Theoretical Criminology.

When our initial Police Lead (who had worked on the development of the project and acted as gatekeeper) left the organization, his replacement, a Chief Inspector with responsibilities for 'academic partnerships' was unable to resist the 'claim' made on the SRA by a key member of the managerial staff to whom we had been alerted. This 'claim' was illustrated not only by being allocated a desk alongside the manager, being introduced initially as a 'new member of the team', and required to fill in a weekly online diary to show times, locations and personnel met and interacted with for the duration of the seven-month secondment, but, by the manager's attempts to co-opt the SRA's research skills into the service of a large-scale internal force reform programme. A huge effort was required on the part of the SRA to establish positive rapport with this manager while maintaining independence from this agenda. The fact is that the SRA never entirely gained the trust of the manager who was so keen to 'manage' her and who could on occasion be a powerful gate-keeper because the manager was actively defending her own territory and authority in a context of rationalisation of police roles and responsibilities, as was made explicit to the SRA after (but nor before) the manager's departure from the force towards the end of the project.

\section{Discussion and Conclusions}

This paper reflected on knowledge transfer or enterprise work with police forces in England in the context of the 'enterprise university', police-academic partnerships and evidence-based policing. We focused on two levels of co-option: internal university pressures and external pressures encountered when engaging with police partners. While 'public criminology' in its myriad forms is undoubtedly a vital part of the academic division of labour, greater reflection is needed regarding the practice, politics, and ethics of this work (Chancer and McLaughlin, 2007). As Lumsden and Winter (2014: 2) argue 'evidence-based research and engagement with the criminal justice system or other powerful institutions must be done in a tempered, 
This is a pre-print version of: Lumsden, K. and Goode, J. (forthcoming) 'Public Criminology, Reflexivity and the Enterprise University: Experiences of Research, Knowledge Transfer, and Co-option with Police Forces.' Theoretical Criminology.

critical and reflexive manner'. Caution is required regarding the ways in which a 'public criminology' can be co-opted into the call for impactful and user-focused research in the context of the entrepreneurial university. We need to be mindful of instances where 'public criminology' might in fact not be called for, and equally, of how we can retain a critical ‘criminological imagination' (Young, 2011) while doing ‘public criminology’.

The challenges faced in trying to retain our critical insight, while publicly engaging with police, highlights the pressures criminologists face in practice. As Burawoy (2005: 11) writes, 'the distinction between public and policy sociology can often blur - sociology can simultaneously serve a client and generate public debate'. This is reflected in an emphasis on research needs as defined by the user. Manning (2005: 39) highlights a tension in police studies between the call for short-term funded research, and longer-term theoretically grounded scholarship and warns against an increasing focus on 'mirror work reflecting the interests of the government of the day'. Smith (2010: 190) argues that post-1992 academia can be seen as 'increasingly rewarding intellectual conformity', and we found that the evidence-based movement exacerbated this. This highlights the risks of 'public criminology' becoming managerialized in the context of research 'impact' in the British higher education context (Loader and Sparks, 2010a). However, it was also clear from our experiences that there were benefits to be had on both sides from collaborative work, and that police partners expected that access to force(s)would result in direct delivery on our part of 'useful' (read: 'cost-saving') knowledge and practical (read: 'aligned with their organizational targets') recommendations.

We found that there was a lack of clarity about the meanings of 'enterprise', 'engagement' and 'impact' in the sense that these are not well-articulated or differentiated in practice by 
This is a pre-print version of: Lumsden, K. and Goode, J. (forthcoming) 'Public Criminology, Reflexivity and the Enterprise University: Experiences of Research, Knowledge Transfer, and Co-option with Police Forces.' Theoretical Criminology.

universities themselves. Individuals tended to use the terms 'enterprise' and 'impact' interchangeably. For us, 'enterprise' has been experienced and understood as a means of generating 'impact' from research (and for universities with income generation as the end goal). So 'enterprise' becomes a process of 'impact' generation. But equally, we experienced this as also opening up future research opportunities and (as below) offering access to the police organizational culture. The lack of articulation and clarity on the part of universities means that 'enterprise', 'impact', 'engagement' and 'research' occupy semantically and discursively shifting ground - which may enhance their power to operate as a disciplinary mechanism (Foucault, 1975), as academics struggle to understand and meet their requirements.

We are reflecting on our experiences of doing 'enterprise' as defined and promoted within a particular university in the English higher education system, and recognise that our experiences may not be shared across the board. However, we would argue that they are a reflection of the growing trend in British higher education and in other Anglophone jurisdictions towards managerialism and a focus on impact (social and economic but ultimately geared towards the latter). The type of collaboration being discussed in this paper has been touched upon previously in literature on police-academic partnerships, including Bradley and Nixon's (2009: 424) acknowledgement of 'intimate and continuous partnership[s] between police and the university system' in Australia, and police and university relations in America (Engel and Whalen, 2010), Scotland (Fyfe and Wilson, 2012), and in Europe. ${ }^{2}$

We were operating in a specific institutional location/context where industry, engineering and business schools largely shaped the university agendas - creating both opportunities for us as 
This is a pre-print version of: Lumsden, K. and Goode, J. (forthcoming) 'Public Criminology, Reflexivity and the Enterprise University: Experiences of Research, Knowledge Transfer, and Co-option with Police Forces.' Theoretical Criminology.

social scientists to 'do' enterprise, but also challenges in relation to how we were expected to operate and what we were expected to deliver in terms of outcomes that can be incompatible with the nature of social science knowledge production and its 'transfer'. Another element of 'audit culture' (Power, 1997; Strathern, 2000) is the way in which those individuals subjected to it, become institutionalized and engage in a form of 'self-discipline'. As Shore (2008: 283) writes: 'this is because of the insidious way it has of implicating all of us in its webs of power: whether it be in the form of annual performance reviews, research assessment exercises, or the competitive ranking of our institutions... we have all bought into the audit culture and allowed it to shape our thinking and our subjectivities'. In this context and from our experiences, this creates space for the potential co-option of 'public criminology' into university/political agendas.

This paper also contributes to discussions of the state of police studies whose empirical, theoretical and methodological agendas are now likely to be set by the organization that should be researched. Police studies risks acting merely as a 'servant of power' (Burawoy, 2004: 1611), with academics holding up a 'mirror' to police organizations, and reaffirming government and state actions, rather than their research acting as a 'motor' for change (Innes, 2004). Moreover, a focus on 'gold standard' methodologies associated with the evidencebased policing movement in the UK (such as randomized control trials and systematic reviews), risks overshadowing or discounting a legacy of seminal criminological/sociological police studies (i.e. ethnographies of policing) (Lumsden and Goode, 2016).

Gaining privileged access to the organizational culture(s) of the police gave us a glimpse into this world and how individuals within it understood and viewed research, academia, and evidence-based policing. Viewing police as consisting of multiple cultures allows us to 
This is a pre-print version of: Lumsden, K. and Goode, J. (forthcoming) 'Public Criminology, Reflexivity and the Enterprise University: Experiences of Research, Knowledge Transfer, and Co-option with Police Forces.' Theoretical Criminology.

'convey the nuances and differences within and between different elements of the police organization and the people who work in it rather than presenting it as homogenous and onedimensional' (Foster, 2003: 196). We had insight into the internal workings of the culture and challenges faced in the wider social and political context, particularly vis-à-vis the impact of financial cuts to policing budgets. The monitoring of the SRA on secondment highlighted tensions in the internal culture between certain gatekeepers who were police officers, and others who were management staff. We were 'co-opted' into the internal conflicts and vulnerability felt by some members of staff in relation to their own organizational role(s), and the wider context of austerity which is reshaping police organizations and professional and management roles within them.

We were also confronted with contestations as to how stakeholders defined 'legitimate knowledge'. Tonry (2010: 787) highlights how knowledge 'must pass successfully through a series of filters if it is to influence policy' and that 'windows of opportunity' are crucial for determining how successful knowledge transfer will be. Rock (2010: 758-759) argues that policymakers are 'rarely amenable to rational guidance' and that criminologists have not 'peered into the black box of the political process but have become observers after the event when policies are neatly packaged, discursively tidied up, agreed and coherent, free of discontinuities, false starts, doubts, falterings, and lacunae'. It is here that Loader and Sparks (2010b: 119) notion of the criminologist as 'democratic under-labourer' is useful for recognising the ways in which criminologists could 'cultivate greater humility in the face of democratic politics'. There is a need to investigate how criminological knowledge relates to and intersects with wider forces 'in shaping how crime problems are defined and acted upon' (Loader and Sparks, 2010b: 120). This includes how this knowledge is used in policy spheres, and 'how this process of knowledge selection and utilization varies across political 
This is a pre-print version of: Lumsden, K. and Goode, J. (forthcoming) 'Public Criminology, Reflexivity and the Enterprise University: Experiences of Research, Knowledge Transfer, and Co-option with Police Forces.' Theoretical Criminology.

cultures' (Loader and Sparks, 2010b: 120). Police-academic partnerships offer opportunities for criminologists to better understand the ways in which knowledge is received, challenged, (de)legitimised and utilised in the context of policing.

Under the auspices of 'new managerialism' and the extensive cuts to public spending experienced by the police and public sector post-2008 recession, an environment has been ushered in which creates a paradox in police and academic partnerships, in that both police forces and academics are under pressure to engage with external partners at the same time as the evidence-base becomes "entangled with "the new public management"' (Hammersley, 2013: 4-5). Although there are undoubtedly benefits to be had, we would also call for caution in a relationship where 'public criminology' risks being co-opted into serving the interests of users and as part of performance management. In this sense, the contribution that criminology can make to research in areas such as policing is valuable for informing police and governmental responses. Despite universities' calls for enterprise work by academics, and research funding council calls for impactful research, there is a unique position faced by (some) criminologists who wish to engage publicly in these activities, if they also wish to challenge the relations and structures of power.

In sum, we call for wider debate concerning the practice, politics, and ethics of (public) engagement, and police-academic partnerships in an age of 'enterprise' and 'public criminologies' (Chancer and McLaughlin, 2007). Like research, public engagement and impact are 'messy' and we need to be mindful of how we can retain the critical sensibility so vital to criminology, while effectively engaging with publics. In tracing our journey of enterprise work with police forces, we have made evident the tension between the need for criminologists to publicly engage in a normative sense, and the risks inherent in the current 
This is a pre-print version of: Lumsden, K. and Goode, J. (forthcoming) 'Public Criminology, Reflexivity and the Enterprise University: Experiences of Research, Knowledge Transfer, and Co-option with Police Forces.' Theoretical Criminology.

institutional culture, in which academics and organizational partners alike are subject to so many internal and external constraints, risking the co-opting of criminological research and 'public criminology' into agendas not of their choosing.

\section{References}

Barak G (2007) Doing newsmaking criminology from within the academy. Theoretical Criminology 11: 191-207.

Bradley D and Nixon C (2009) Ending the 'dialogue of the deaf': evidence and policing policies and practices. An Australian case study. Police Practice and Research 10(5-6): 423435.

Burawoy M (2004) Public sociologies: contradictions, dilemmas and possibilities. Social Forces 82(4): 1603-1618.

Burawoy M (2005) For public sociology. American Sociological Review 70(1): 4-28.

Cain M (1979) Trends in the sociology of policework. International Journal of Sociology of Law 7: 143-167.

Cain M (1993) Some go back, some go forward. Contemporary Sociology 22(3): 319-324.

Canter D V (2004) A tale of two cultures: a comparison of the cultures of the police and academia. In: Adlam R and Villiers P (eds) Policing, A Safe, Just and Tolerant Society: An International Model. Winchester, UK: Waterside Press, pp.109-121.

Carrabine E, Lee M and South N (2000) Social wrongs and human rights in late modern Britain: social exclusion, crime control and prospects for a public criminology. Social Justice 27: 193-211.

Chan J (2000) Globalization, reflexivity and the practice of criminology. Australian \& New Zealand Journal of Criminology 33(2): 118-135. 
This is a pre-print version of: Lumsden, K. and Goode, J. (forthcoming) 'Public Criminology, Reflexivity and the Enterprise University: Experiences of Research, Knowledge Transfer, and Co-option with Police Forces.' Theoretical Criminology.

Chancer L and McLaughlin E (2007) Public criminologies: diverse perspectives on academia and policy. Theoretical Criminology 11(2): 155-173.

Chevigny P (1969) Police Power. New York: Pantheon Books.

Currie E (2007) Against marginality: arguments for a public criminology. Theoretical Criminology 11(2): 175-190.

Engel R S and Whalen J L (2010) Police-academic partnerships: ending the dialogue of the deaf, the Cincinnati experience. Police Practice and Research 11(2): 105-116.

Fleming J (2012) Changing the way we do business: reflecting on collaborative practice. Police Practice and Research 13(4): 375-388.

Foster J (2003) Police cultures. In: Newburn T (ed) Handbook of Policing. Cullompton: Willan, pp.196-227.

Foster J and Bailey S (2010) Joining forces: maximising ways of making a difference in policing. Policing 4(2): 95-103.

Foucault M (1975) Discipline and Punish. London: Penguin.

Fyfe N R and Wilson P (2012) Knowledge exchange and police practice: broadening and deepening the debate around researcher-practitioner collaborations. Police Practice and Research 13(4): 306-314.

Garland D and Sparks R (2000) Criminology, social theory and the challenge of our times. British Journal of Criminology 40(2): 189-204.

Gattone C F (2006) The Social Scientist as Public Intellectual. Oxford: Rowman \& Littlefield.

Gelsthorpe L and Morris A (eds) (1990) Feminist Perspectives in Criminology. Milton Keynes: Open University Press.

Goldstein H (1990) Problem-Oriented Policing. New York: McGraw-Hill. 
This is a pre-print version of: Lumsden, K. and Goode, J. (forthcoming) 'Public Criminology, Reflexivity and the Enterprise University: Experiences of Research, Knowledge Transfer, and Co-option with Police Forces.' Theoretical Criminology.

Goode J and Lumsden K (2016) The mcdonaldisation of police-academic partnerships:

Organisational and cultural barriers encountered in moving from research on police to research with police. Policing \& Society, iFirst, doi 10.1080/10439463.2016.1147039.

Hall S, Critcher C, Jefferson T, Clarke J and Roberts B (1978) Policing the Crisis. London: Macmillan.

Hammersley M (2013) The Myth of Research-Based Policy and Practice. London: Sage.

HEFCE (2016) Knowledge exchange funding - HEIF. URL (accessed 3 August 2016): http://www.hefce.ac.uk/kess/heif/

Innes M (2010) A 'mirror' and a 'motor': researching and reforming policing in an age of austerity. Policing 4(2): 127-134.

Jewkes Y (2012) Autoethnography and emotion as intellectual resources: doing prison research differently. Qualitative Inquiry 18(1): 63-75.

Jupp V (1989) Methods of Criminological Research. London: Unwin Hyman.

Lea J and Young J (1984) What is to be Done about Law and Order? London: Pluto Press.

Liebling A (1999) Doing research in prison: breaking the silence? Theoretical Criminology 3(2): $147-173$.

Loader I and Sparks R (2010a) What is to be done with public criminology? Criminology \& Public Policy 9(4): 771-781.

Loader I and Sparks R (2010b) Public Criminology? London: Routledge.

Lumsden K (2016) The shifting legitimacy of knowledge across academic and police/practitioner settings: Highlighting the risks and limits of reflexivity. In: Armstrong S, Blaustein J and Henry A (eds) Reflexivity and Criminal Justice: Intersections of Policy and Practice, Basingstoke: Palgrave Macmillan, pp. 191-213. Pre-print version (accessed December 2016): 
This is a pre-print version of: Lumsden, K. and Goode, J. (forthcoming) 'Public Criminology, Reflexivity and the Enterprise University: Experiences of Research, Knowledge Transfer, and Co-option with Police Forces.' Theoretical Criminology. https://www.academia.edu/14822884/The Shifting Legitimacy of Knowledge Across Aca demic and Police_Practitioner_Settings_Highlighting the Risks_and_Limits_of_Reflexivit y

Lumsden K and Goode J (2016) Policing research and the rise of the 'evidence-base': Police officer and staff understandings of research, its implementation and 'what works'. Sociology iFirst, doi 10.1177/0038038516664684.

Lumsden K and Winter A (eds) (2014) Reflexivity in Criminological Research. Basingstoke: Palgrave Macmillan.

McLaughlin E (2007) The New Policing. London: Sage.

Manning P K (2005) The study of policing. Police Quarterly 8(1): 23-43.

Mason G and Stubbs J (2010) Feminist approaches to criminological research. In: Gadd D, Karstedt S and Messner S (eds) The SAGE Handbook of Criminological Research Methods. London: Sage.

Oakley A (1981) Interviewing women: a contradiction in terms. In: Roberts H (ed) Doing Feminist Research. London: Routledge \& Kegan Paul, pp.30-61.

O’Neill M (2014) The slow university: work, time and well-being. Qualitative Forum 15(3). URL (accessed 27 July 2016): $\quad \underline{\text { http://www.qualitative- }}$ research.net/index.php/fqs/article/view/2226/3696

Power M (1997) The Audit Society. Oxford: Oxford University Press.

Punch M (1985) Conduct Unbecoming. London: Tavistock.

Rock P (2010) Comment on 'public criminologies'. Criminology \& Public Policy 9(4): 751767.

Rock P (2014) The public faces of public criminology. Criminology and Criminal Justice 14: 412-433.

Sheptycki J (1994) It looks different from the outside. Policing 10(2): 125-133. 
This is a pre-print version of: Lumsden, K. and Goode, J. (forthcoming) 'Public Criminology, Reflexivity and the Enterprise University: Experiences of Research, Knowledge Transfer, and Co-option with Police Forces.' Theoretical Criminology.

Shore C (2008) Audit culture and illiberal governance: universities and the politics of accountability. Anthropological Theory 8(3): 278-298.

Smith K (2010) Research, policy and funding - academic treadmills and the squeeze on intellectual spaces. British Journal of Sociology 61(1): 176-195.

Stanko B A (2008) The ill at ease or the uneasy fit? Mapping knowledge onto policy onto practice within a political maelstrom. Criminal Justice Matters 72(1): 12-13.

Stanko B A (2007) From academia to policy making: changing police responses to violence against women. Theoretical Criminology 11(2): 209-219.

Strathern M (ed) (2000) Audit Cultures. London: Routledge.

Taylor Y (ed) (2014) The Entrepreneurial University. Basingstoke: Palgrave Macmillan.

Tittle C (2004) The arrogance of public criminology. Social Forces 82(4): 1639-1643.

Tonry M (2010) 'Public criminology' and evidence-based policy. Criminology and Public Policy 9: 783-797.

Uggen C and Inderbitzin M (2006) Public criminologies. Paper presented at the 2006 Annual Meeting of the American Sociological Association, Montreal.

Uggen C and Inderbitzin M (2010) Public criminologies. Criminology and Public Policy 9: $725-749$.

Wacquant L (2011) From 'public criminology' to the reflexive sociology of criminological production and consumption: a review of Public Criminology? by Ian Loader and Richard Sparks. British Journal of Criminology 51: 438-448.

Wilkinson S (2010) Research and policing - looking to the future. Policing 4(2): 146-148. Wilson J G and Kelling G (1982) Broken windows. Atlantic Monthly 249: 29-38.

Young J (2011) The Criminological Imagination. Cambridge: Polity Press. 
This is a pre-print version of: Lumsden, K. and Goode, J. (forthcoming) 'Public Criminology, Reflexivity and the Enterprise University: Experiences of Research, Knowledge Transfer, and Co-option with Police Forces.' Theoretical Criminology.

Notes

${ }^{1}$ For 2015-16 and 2016-17 allocations are performance based and institutions are eligible to receive an allocation if they exceed a $£ 250,000$ allocation threshold related to their external income earnings and performance of the sector overall (HEFCE, 2016).

${ }^{2}$ For instance, also reflected in the creation of the European Police Research Institutes Collaboration (EPIC) which aims to bridge the gap between police policy and practice, and scientific knowledge and research. 